\title{
Mechanisms of Non-Steroid Anti-Inflammatory Drugs Action on Acid-Sensing Ion Channels of Hippocampal Interneurons
}

\author{
N. A. Dorofeeva ${ }^{a}$, O. I. Barygin ${ }^{a}$, A. Staruschenko ${ }^{b}$, L. G. Magazanik ${ }^{a}$, and K. V. Bolshakov ${ }^{a}$ \\ ${ }^{a}$ Sechenov Institute of Evolutionary Physiology and Biochemistry RAS, pr. M. Toreza, 44, St.Petersburg, 194223 Russia; \\ email: k.bolshakov@biotechnologies.ru \\ ${ }^{b}$ Medical College of Wisconsin, Physiology and Kidney Disease Center, Milwaukee, Wisconsin, USA
}

DOI: $10.1134 / \mathrm{S} 1990747809030179$

The inhibitiory action of non-steroid anti-inflammatory drugs (diclofenac, ibuprofen, aspirin and salicylic acid) was investigated on acid-sensing ion channels (ASIC) in isolated hippocampal interneurons and on recombinant homo- and heteromeric ASICs expressed in $\mathrm{CHO}$ cells. Diclofenac and ibuprofen inhibited proton-induced currents in a range of concentrations from $100 \mu \mathrm{M}$ to $3 \mathrm{mM}\left(\mathrm{IC}_{50}\right.$ were $622 \pm 34 \mu \mathrm{M}$ and $3.42 \pm$ $0.50 \mathrm{mM}$ respectively). The non-competitive inhibition was fast and fully reversible for both drugs. Aspirin and salicylic acid were ineffective up to $500 \mu \mathrm{M}$. Diclofenac and ibuprofen decreased the amplitude of proton-evoked currents and slowed the rate of currents decay with a good correlation between these two effects $(r=0.99, p<0.05$ for both drugs). Simultaneous application of acid solution $(\mathrm{pH}=5.5)$ and diclofenac was required for its inhibitory action. Unlike amiloride, nonselective inhibitor of $\mathrm{ENaC} / \mathrm{Deg}$ family of sodium channels, the action of diclofenac was voltage-independent. No competition was found between diclofenac and amiloride. Analysis of the action of diclofenac and ibuprofen on activation and desensitization of ASICs showed that diclofenac but not ibuprofen shifted the steady-state desensitization curve to more alkaline $\mathrm{pH}$ values. The reason for this shift was slowing down the recovery from desensitization of ASICs. Thus, diclofenac may serve as a neuroprotective agent during pathological conditions associated with acidification of extracellular environment.

The work was supported the Russian Foundation for Basic Research (project no. 05-04-49770), Grant for Scientific Schools (5575.2006.4), and Program of Molecular Cellular Biology. 